\title{
Implementation of the Training Program on Retooling of Personnel of the Center for Health Development Calabarzon, Philippines
}

\author{
Carl Abelardo T. Antonio, MD, MPH, ${ }^{1,2}$ Eleanor C. Castillo, DrPH, ${ }^{3}$ \\ Carmelita C. Canila, MD, MPA, ${ }^{1}$ Richard S. Javier, MBA-H, ${ }^{1}$ Racel G. Carreon, MM, ${ }^{4}$ \\ Jennifer Christina T. Tiu, MP, ${ }^{5}$ Ma. Sophia Graciela L. Reyes ${ }^{6}$ and Ernesto R. Gregorio Jr., MPH ${ }^{3,7}$ \\ ${ }^{1}$ Department of Health Policy and Administration, College of Public Health, University of the Philippines Manila, Manila, Philippines \\ ${ }^{2}$ Department of Applied Social Sciences, The Hong Kong Polytechnic University, Kowloon, Hong Kong \\ ${ }^{3}$ Department of Health Promotion and Education, College of Public Health, University of the Philippines Manila, Manila, Philippines \\ ${ }^{4}$ Administrative Office, Management Support Division, Center for Health Development IV-A, Quezon City, Philippines \\ ${ }^{5}$ Human Resource Development Service, Management Support Division, Center for Health Development IV-A, Quezon City, Philippines \\ ${ }^{6}$ College of Public Health, University of the Philippines Manila, Manila, Philippines \\ ${ }^{7}$ Department of Global Health, School of Health Sciences, Faculty of Medicine, University of the Ryukyus, Okinawa, Japan
}

\begin{abstract}
Background. The College of Public Health, University of the Philippines Manila (CPH-UPM) was engaged by the Center for Health Development Calabarzon (CHD 4A) to design, implement and manage the retooling of their personnel following implementation of Executive Order No. 336 on the rationalization of the Philippine government's executive branch.
\end{abstract}

Objective. To describe the training design and present outputs of the training modules designed for the CHD 4A staff.

Methods. We reviewed the project documentation, which included the inception report, minutes of meetings, training modules, and post-training reports. Abstracted information was validated through internal discussion by a core group, which had representatives from the two organizations involved from project inception to close-out.

Results. The design, development and implementation of the training were the product of collaborative efforts between CHD 4A and the technical team from the College of Public Health, University of the Philippines Manila. Technical staff of CHD 4A were trained in the competency areas in which gaps between the expected and perceived level of performance across all salary grades were highest: results orientation, planning and organizing, technical expertise, quality service focus, coordination and networking, and managing change. Nine training courses were implemented from May to July 2016, which was attended by 230 participants. All training modules were highly rated by participants (range: 3.60 to 3.85) based on a four-point scale, with 4 as the highest rating and 1 as the lowest. Comparison of pre- and post-tests for the modules on coordination and networking, and managing change showed a statistically significant increase in scores at the conclusion of their respective sessions.

Conclusion. The design of a training program for an organization's personnel must be tailor-fit to and answer the needs of its employees. Trainers must be willing to make dynamic changes and adapt to immediate feedback from participants. The implementing party and organization itself must both ensure thorough evaluation of the effects of the training to achieve the organization's long-term goals.

Key Words: Staff development, Teaching, Education, Workforce

\section{INTRODUCTION}

Corresponding author: Carl Abelardo T. Antonio, MD, MPH Department of Health Policy and Administration College of Public Health University of the Philippines Manila

625 Pedro Gil Street, Ermita, Manila 1000, Philippines Email: ctantonio@up.edu.ph
The Rationalization Plan of the Philippine government's executive branch mandated under Executive Order No. 336 was conceptualized to realign personnel based on qualification, performance, and competencies. In response to 
the reorganization brought about by this plan, the College of Public Health, University of the Philippines Manila (CPHUPM) was engaged by the Center for Health Development Calabarzon (CHD 4A) to design, implement and manage the retooling of their personnel. ${ }^{1}$

A training needs assessment (TNA) with a competency gap analysis was conducted prior to the implementation of the retooling in order to tailor-fit the modules to the needs of the organization, details of which are described in a separate paper. ${ }^{2-4}$ This TNA identified specific skill areas and competencies among the CHD 4A personnel, ${ }^{5}$ from which training modules were developed and implemented.

In this paper, we provide an overview of the content and describe outputs of the training activities implemented over a 10-month period between May 2015 and March 2016. Our purpose is to contribute to the local body of literature on training design and management, provide a starting point for other practitioners in the field, and serve as potential academic reference for courses on learning and development, human resource management, and professional education.

This article describes the training design (including content and the training process) and presents the outputs of the training modules designed for the CHD 4A staff participant reaction and learning.

\section{METHODS}

Information presented in this manuscript were collated from project documentation, which included the inception report, minutes of meetings, training modules, and posttraining reports. The author-team abstracted information from these sources in order to develop an account of the process of training design and module development, and a description of the training outputs. Results were validated through internal discussion by a core group representing the two organizations who were involved from project inception to close-out.

The success of the training program was evaluated using Level 1 (Reaction) and Level 2 (Learning) of Kirkpatrick's Four-Level Training Evaluation Model. ${ }^{4}$ Reactions of participants were primarily drawn from the daily and posttraining evaluation. They were asked which topics they liked the most and the least, how effective they perceived the speakers, and the importance of the subjects discussed. These forms were accomplished by participants anonymously (i.e., no personal identifiers were collected in the forms). What participants learned were measured through their workshop outputs (applicable to most modules) and through pre- and post-test (for the Coordination and Networking, and Managing Change modules). Anonymized data (i.e., participants only identifiable through codes for pairing of pre- and post-test scores) for the latter were consolidated and analyzed using Microsoft Excel 2013. The observed differences in scores were tested for significance using a twotailed $\mathrm{t}$-test for paired samples.

\section{RESULTS}

\section{Considerations in training design}

A consultative meeting between representatives of CPH-UPM and CHD 4A was held in October 2015 to discuss and validate the results of the training needs analysis and to tailor a training course based on the findings. Participants in the validation meeting indicated a preference for two to three days of training, in a venue separate from their office. They also preferred a staggered, modular, andragogical format that would tailor discussions to functional groups, focus examples on the government agency setting, and provide ample time for sharing experiences. Preferred methods of assessment were role playing, case studies, demonstrations, and workshops. A monitoring and evaluation tool was recommended to be included in the module (for Kirkpatrick's Evaluation Levels 1 and 2, which are Reaction and Learning, respectively), while monitoring for Levels 3 and 4 (Behavior and Results, respectively) were initiated by CHD 4A in partnership with CPH-UPM at the time of writing (i.e., around July 2018, or approximately two years after the last training activity. This time period was selected as the evaluation team were of the considered opinion that this interval allowed for sufficient embedding of knowledge and skills learned from the training event into workplace activities).

It was agreed upon at this consultative meeting that personnel would undergo training for all the priority competency areas to be covered for the engagement. Personnel who would attend the training sessions were to be selected by the human resource team of $\mathrm{CHD} 4 \mathrm{~A}$. The end goal of the training program would be to lead regional personnel towards comprehensive individual career plans. These plans would outline the goals of individual employees with respect to their learning and development, as well as corresponding activities and timelines to support the achievement of this goal.

Technical staff members were prioritized for the engagement for two reasons: (a) they are most affected by the rationalization plan in terms of placement in new positions requiring a different skill set, and (b) they particularly have a clearly defined set of competencies and indicators within the $\mathrm{DOH}$.

\section{Module development}

The priority competency areas for training were the competencies in which gaps between the expected and perceived level of performance for technical staff across all salary grades were highest: results orientation, planning and organizing, technical expertise, quality service focus, coordination and networking, and managing change. These were the bases for the selection and development of modules, which were formulated from October 2015 to January 2016, and validated in another two consultative meetings at the CHD 4A office in February 2016. 
The CPH-UPM team identified individuals among the faculty, as well as colleagues and experts from outside the academe, with experience in the module content. These individuals were requested to design the training, bearing in mind the following constraints: (a) the content of each module should be based on the descriptors for each competency as provided by the $\mathrm{DOH}$; (b) all modules should use participatory teaching-learning strategies, and should focus on the development of practical skills that can be used in the workplace; and (c) the number of hours for each module needed to be estimated from the breadth of each competency, as well as administrative constraints.

The design and outline of the module content were then subjected to internal peer review. Once the project team deemed the proposed content to be consistent with identified competency descriptors, the writers then proceeded to develop the modules. Some were derived from existing training activities of each individual writer, but others had to be developed anew to ensure alignment with the descriptors of the identified competencies.

The completed modules were then subjected to two levels of review: (a) within the CPH-UPM team, and (b) with CHD 4A. The final modules incorporated the comments and suggestions provided by these two groups.

Both parties agreed to have multiple batches or runs per module to accommodate personnel who could not afford to leave their respective offices and/or field work. The first training session of each module was considered as a pilot implementation with the opportunity for modification of the subsequent batches. The project team also adopted an approach of adaptation and learning where daily and end-of-module evaluation results were used to implement changes in content or administration to address concerns raised by participants.

\section{Modules}

Modules ran from as short as 5 to as long as 12 hours each and utilized a variety of teaching-learning strategies, ranging from lectures to simulations and small group activities. An overview of the training design for each module is provided in Table 1 , and briefly described below.

\section{Quality Service Focus}

According to $\mathrm{DOH}$ standards, this competency is defined as "quality service and client satisfaction through continuous improvement of processes, policies, and procedures." This module focuses on developing one's particular life goals and how these may be achieved. ${ }^{6,7}$ If personal goals are aligned with those of the organization, then appreciation is more likely to be granted at work. If this can be done with a positive attitude, assertiveness, and desire to continually look for ways to improve, then career prospects are likely to be good. The objective of this module was for the CHD 4A staff to develop the capacities to create a continuous learning environment for self and others that could encourage people to carry out their action plans.

\section{Planning and Organizing}

This competency had been defined by the $\mathrm{DOH}$ as "the ability to align provincial health plans with the national health agenda in order to support the achievement of national health goals." The devolution of health services more than two decades ago resulted to a greater level of autonomy in the planning, implementation and evaluation of health services at the sub-national levels (i.e., province, city, municipality, and barangay). On the one hand, this meant that health services can be better oriented towards the needs of the area as planners are more aware and even immersed in the local shapers, drivers and barriers to attainment of better health outcomes. The reality, however, is that fragmentation of activities and outcomes can, and do, take place given that there are more than 1,500 local government units defining and implementing their own health agenda. Furthermore, the Philippine government, through the National Economic and Development Authority and the $\mathrm{DOH}$, had also formulated national goals in the form of the Philippine Development Plan and the National Objectives for Health, both of which identify the priority areas and concerns of the current dispensation. Finally, there are international agreements in health to which the country has committed itself, lending another level of complexity to the definition of the Philippine health agenda.

Thus, there is a pressing need to ensure that health plans developed at the sub-national level are aligned with the broader national health goals; without sacrificing the plan of activities unique to the different provinces, cities and municipalities. The CHD is in the best position for this undertaking, as they are organizationally situated at the interface of the national and local governments. This module will introduce to the learner the logical framework approach as a planning framework to attain efficiency and effectiveness in the Philippine health system.

\section{Results Orientation}

Results orientation has found its way into public management in developed and developing countries many decades ago. In the Philippines, the DOH defined results orientation in its competency dictionary and rubrics in 2004-2005 as "setting, striving to achieve and achieving challenging tasks," while in the Learning and Development Needs Assessment Tool (version 3-45) further defined as "the ability to set, strive, and achieve challenging organizational goals and objectives for optimum customer satisfaction."

Producing results is one of the World Health Organization's (WHO) seven core competencies for human resources services. Under its Global Competency Model, it is defined as a competency that "produces and delivers quality results, action-oriented and committed to achieving outcomes." ${ }^{8}$ This module sought to enable the staff and managers to demonstrate their commitment to defined or agreed results and to apply what they had learned immediately. The key behaviors that participants need to 
Table 1. Overview of training design for five modules

At the end of this module, participants are expected to:

- Create a continuous learning environment for self and others that would encourage people to carry out their action plans

- Lead and participate in high -level training seminars

- Demonstrate commitment by establishing a mechanism, maintaining financial and personal support, and providing time and staff development

- Recognize and reward people who accomplished their action plan

- Be qualified to teach and mentor others

Planning \& Organizing

This module will contribute to the attainment of the following learning outcomes:

- Appraise existing local health plans as to their alignment with defined national agenda

- Support local health planners in the generation of health plans consistent with national health goals

- Work efficiently with stakeholders from different sectors in the preparation of local health plans

- Communicate effectively with stakeholders in health in both written and oral forms

- Active lectures

- Self-Awareness

- Communication

- Teaching, Mentoring, Coaching

- Customer and Market Knowledge

- Problem Solving

- Conflict Management

- Customer Service

- Total Quality Management

- Culture Change / Culture of Appreciation
- Planning as a Management Function - Lecture-discussion

- Logical Framework Approach to Planning

- Preparation Stage of Planning: Problem Identification and

Prioritization

- Stakeholder Analysis

- Problem Analysis

- Objectives Analysis

- Design of Program / Project Structure using the Log Frame

- Transitioning from Planning to Implementation

\section{Results Orientation}

The basic underlying lynchpin of this module is operational principles, as follows:

- What gets measured gets done; What gets documented gets measured;

- If you measure results, you will know success from failure; if you do not measure results, you will not realize success from failure;

- If you are informed of what is successful, you will know whom to reward; if you cannot reward success, you are possibly rewarding failure;

- If you can differentiate what is successful from failure, you will learn from it; if you cannot differentiate the two, you cannot correct your problems.

Coordination \& Networking

At the end of this module, participants are expected to:

- Articulate correct concepts on networking and coordination;

- Explain the processes involved in networking and coordination;

- Demonstrate how to conduct a stakeholder analysis;

- Design a networking and coordination action plan;

- Implement the networking and coordination plan;

- Evaluate the effect of the plan in relation to creation of networks and linkages;

- Submit a written report of the networking and coordination activity.
- Management for Development Results

- Fostering Strategic Partnership towards Achieving Outcomes / Management of Outcomes
- Question \& answer segments

- Stakeholder analysis matrix mapping

- Workshops (case analysis)

- Plenary presentations

- Small group activities

- Workshops

- Conceptual Coordination and Networking

- Understanding Different Personality Types

- Process of Networking and Coordination

- Factors and Strategies for Effective Networking and Coordination

- Development, Presentation, and Critiquing of Networking \& Coordination Plan
- Active Lectures

- Personal network mapping

- Video clip presentations

- Self-assessment

- Question \& answer segments

- Case analysis

- Case studies and group sharing

- Simulation activities

- Presentation of outputs

- Open forum

- Broken square game

- Group reporting

\section{Managing Change}

At the end of this module, participants are expected to:

- Discuss some basic concepts in change management;

- Apply selected theories in designing and implementing a change management program;

- Explain Kotter's 8 Steps Change Model in implementing the change management program using.

- Using a vignette, demonstrate the competencies related to Kotter's 8 Steps Change Model in implementing the change management program.

- Introduction to Managing Change

- Basic Concepts in Change Management

- Theories / Models used in Change Management

- Steps in Change Management

- Reducing Resistance to Change
- Nominal group process

- Lecture-discussion

- Case vignette

- Role-play 
demonstrate in this training are an amalgamation based on the $\mathrm{DOH}$ competency dictionary, the WHO competency model and Organisation for Economic Co-operation and Development's outcome-focused budgeting.

\section{Coordination and Networking}

Improvement of the country's health status requires a workforce that has the ability to connect, link, and relate effectively to people in all walks of life and societies at all levels and settings. The primary purpose of this module was to enhance knowledge and attitudes, and develop skills in networking and coordination. Basic concepts, theories and principles, significance of, processes and strategies in networking and coordination were discussed. In addition, concepts on stakeholder analysis were emphasized. Strategies and exercises for the development and acquisition of skills related to networking and coordination such as building and sustaining relationships, converging common interests, cultivating effective networks, stakeholder analysis, building support base, and negotiation skills were carefully crafted. ${ }^{9} \mathrm{~A}$ networking and coordination plan and report were the final outputs desired for successful completion of this module.

\section{Managing Change}

More than two decades had passed since the devolution of health services to local government units. Through all these years, the $\mathrm{DOH}$ was able to achieve substantial gains in improving the health of the Filipino people. However, amidst these gains were challenges which were both internal and external to the organization. Changes in management, policies, organizational structure, and program focus and priorities were some of the challenges that had affected and continued to affect the effectiveness of the organization. These changes were bound to happen and if the department wants to thrive as an organization, they should be able to anticipate, plan and prepare for such changes. ${ }^{10-12}$ Based on the results of the training needs assessment done among CHD 4A staff in 2015, it was found that managing change was one of the competencies that had the widest gap. Hence, an intervention to respond to this need was imperative.

This module was designed to improve the ability of program managers of the CHD $4 \mathrm{~A}$ to develop and manage a structured approach to transitioning individuals, groups and the organization from a current state to a desired state.

\section{Training Implementation}

The project team, together with the CHD 4A, paired modules that were perceived to be logically linked, or competencies that built on top of one another (i.e., a competency in one area was a pre-requisite for another.) This resulted in three module groups: (1) Quality Service Focus (standalone), (2) Planning and Organizing, and Results Orientation, and (3) Coordination and Networking, and Managing Change.
While a standard training module was used as a starting point, training sessions were still customized based on the composition of the training participants, which were determined by the project team on the first day of training (or in some cases, a day prior.) In instances where the training team assessed the participants as having more experience in an area, or where they had received feedback that participants already knew one skill from having learned it in a related training session between the TNA and this activity, some of the sessions outlined in the module were skipped. Each daily session started with expectations setting in the morning, followed by the program proper consisting of activities that varied per module, and concluded with the completion of an evaluation form to rate the workshop content and organization.

\section{Training Output}

Nine training courses were implemented from May to July 2016, which was attended by 230 participants. Table 2 shows the number of participants per batch that attended each training module.

Each module was conducted in batches consisting of approximately $20 \mathrm{CHD} 4 \mathrm{~A}$ personnel each, and each batch received training sessions distributed over a span of two to three days. The decision to distribute the sessions in this manner was based on several administrative and budgetary constraints.

Project participants were a mix of administrative officers and assistants, legal managers, licensing officers, dormitory managers, accountants, nurses, medical officers and rural health physicians, midwives, medical technologists, entomologists, regulation officers, health program officers, pharmacists, program coordinators, engineers, development management officers, and statisticians.

\section{Training Evaluation (Level 1 and Level 2)}

\section{Level 1: Reaction}

At the end of each session, all participants were asked to evaluate certain aspects of the workshop, including the venue and accommodations, meals, and workshop content.

Table 2. Number of participants per module group and batch

\begin{tabular}{ll}
\multicolumn{1}{c}{ Module / Batch } & No. of participants \\
Quality Service Focus & \\
Batch 1 & 18 \\
Batch 2 & 28 \\
Batch 3 & 30 \\
\hline Planning \& Organizing / Results Orientation & \\
Batch 1 & 26 \\
Batch 2 and 3 & 48 \\
Batch 4 & 22 \\
\hline Coordination \& Networking / Managing Change & \\
Batch 1 & 22 \\
Batch 2 & 30 \\
\hline
\end{tabular}


Table 3. Mean overall ratings for the evaluation of each training module

\begin{tabular}{lccc}
\multirow{2}{*}{ Module } & \multicolumn{3}{c|}{ Overall rating (Mean \pm SD) } \\
\cline { 2 - 4 } & Batch 1 & Batch 2 & Batch 3 \\
Quality Service Focus & $3.74( \pm 0.12)$ & $3.75( \pm 0.12)$ & $3.88( \pm 0.04)$ \\
Planning \& Organizing and Results Orientation & $3.61( \pm 0.21)$ & $3.71( \pm 0.13)$ & $3.81( \pm 0.08)$ \\
Coordination \& Networking and Managing Change & $3.74( \pm 0.05)$ & $3.63( \pm 0.20)$ & - \\
\hline
\end{tabular}

Table 4. Pre- and post-test scores for module participants ( $a=0.05$ )

\begin{tabular}{llcrl}
\multicolumn{1}{c}{ Module } & N & $\begin{array}{c}\text { Pre-test scores } \\
\text { Mean }( \pm \text { SD) }\end{array}$ & $\begin{array}{c}\text { Post-test scores } \\
\text { Mean }( \pm \text { SD) }\end{array}$ & p-value \\
\hline Managing Change (Batch 1) & 30 & $3.77( \pm 1.70)$ & $11.20( \pm 1.73)$ & $<0.001$ \\
Managing Change (Batch 2) & 22 & $3.64( \pm 1.36)$ & $8.23( \pm 1.27)$ & $<0.001$ \\
Coordination and Networking & 21 & $3.10( \pm 1.22)$ & $8.81( \pm 1.44)$ & $<0.001$ \\
\hline
\end{tabular}

A four-point scale was used, with 4 as the highest rating and 1 as the lowest. Table 3 shows the overall rating for each module given by each batch of participants. The data shows that all training modules were highly rated by participants (range: 3.60 to 3.85 ).

\section{Level 2: Learning}

All participants of the modules on Coordination and Networking, and Managing Change took part in pre- and post-module examinations in order to measure how much they learned after each module. A paired two-tailed test was used to analyze the data. All participants were shown to have increased post-module scores at the conclusion of their respective sessions. The observed differences in their scores were found to be statistically significant, as shown in Table 4.

\section{DISCUSSION AND CONCLUSIONS}

The five competency areas - quality service focus, planning and organizing, results orientation, coordination and networking, and managing change - given in three training modules were evaluated positively by the participants. The module that had the most positive reception overall was on quality service focus. When participants were asked to cite their least favorite topics given per module, most of those who attended the quality service focus module cited that they had no least favorite choice. On the other hand, some participants who attended the latter two module groups cited several topics (e.g. networking case analysis, logic framework) as too difficult or confusing, or said that the concepts had already been implemented in their internal programs. This may offer one explanation as to why the overall rating for the Quality Service Focus module is higher than those of the other two module groups.

A collaborative and comprehensive model was adopted by the team in the development of the training design and the modules to ensure fitness of the training content for the needs of the organization requesting the training. The $\mathrm{CPH}$ trainers and faculty worked hand-in-hand with the CHD 4A officials to tailor-fit the program to the latter's personnel. This was done to ensure optimum absorption of information from learning materials and responsiveness to the sessions, as compared to pre-configured training activities offered by other institutions. The incorporation of quality improvement in the training, as manifested by the multiple points for eliciting participant feedback and the institution of corrective actions within and between each module, was key in ensuring the success of the training program as a whole for all participants.

The dynamic nature of program implementation where participants' feedback was incorporated in the module design for succeeding batches of participants, however, meant that there were differences in the sessions and activities offered to each batch per module. This may preclude the comparability between iterations of the same training module.

This article only discusses the Reaction and Learning levels of Kirkpatrick's model of evaluation (levels 1 and 2); how well the participants applied what they learned in everyday operations (Behavior) and how key performance indicators and ideal outcomes were achieved as a result of an increase in staff competence (Results). Thus, long-term effects have not yet been measured.

The design of a training program for an organization's personnel, particularly those working in government, must be tailor-fit and answer the needs of its employees to have a lasting impact. Trainers must be willing to make dynamic changes and adapt to immediate feedback from participants, and both the implementing party and the organization itself must ensure the thorough evaluation of the effects of the training for the organization's long-term goals to be achieved.

\section{Acknowledgments}

The authors were supported in the implementation of the "Retooling Project" and the publication of this work by the executives of the Center for Health Development IV-A (Dr. Nestor F. Santiago, Jr., Dr. Corazon I. Flores, Dr. Rio L. Magpantay, and Dr. Noel G. Pasion), the staff of the Human Resource Development Service (Katherine A. Villareal, Maricel B. Reyes, Joey John A. Antazo), and the training support team (Andrea Marie C. Millara, Joceh Sarah M. Anonuevo, Gladys Larissa V. Armada, John Robert 
C. Medina, Jerome E. Villacorta, Charmaine M. Cañizares, Barry C. Gundayao).

All views and opinions expressed in this article are those of the authors and do not necessarily reflect the official policy or position of the organizations they represent.

\section{Statement of Authorship}

All authors participated in data collection and/or analysis, and approved the final version submitted.

\section{Author Disclosure}

At the time of writing, Ms. Carreon and Ms. Tiu are employed by the Center for Health Development IV-A.

All other authors (with the exception of Ms. Reyes) were involved in the design and implementation of the retooling training courses, which is the subject of this paper.

\section{Funding Source}

This work was funded by the Center for Health Development Calabarzon.

\section{REFERENCES}

1. Executive Order No. 366, s.2004. Directing a strategic review of the operations and organizations of the Executive Branch and providing options and incentives for government employees who may be affected by the rationalization of the functions and agencies [Internet]. 2004 Oct 04 [cited 2019 Apr 24]. Available from https://www.official gazette.gov.ph/2004/10/04/executive-order-no-366-s-2004/.

2. Kern DE, Thomas PA, Patricia A, Hughes MT. Curriculum development for medical education: a six-step approach. Baltimore, MD: Johns Hopkins University Press; 2015.
3. Gaspard J, Yang CM. Training needs assessment of health care professionals in a developing country: the example of Saint Lucia. BMC Med Educ. 2016; 16:112. doi: 10.1186/s12909-016-0638-9.

4. Kirkpatrick JD, Kirkpatrick WK. Kirkpatrick's four levels of training evaluation Alexandria, VA: ATD Press; 2016.

5. Castillo EC, Antonio CT, Carreon RG, Tiu JT, Reyes ML, Quizon RR, Gregorio ER. Assessment of core and functional competencies of technical personnel of the Center for Health Development Calabarzon, Philippines. Acta Med Philipp. 2021 Mar 02. doi: 10.47895/amp.vi0.3004.

6. NHS Leadership Academy. Leadership framework - Summary of domains, elements, and stages [Internet]. 2011 [cited 2019 Apr]. Available from: https://www.leadershipacademy.nhs.uk/wp-content/ uploads/2012/11/NHSLeadership-Leadership-Framework-LFQuick-Reference-Guide-Summary-of-Domains-Elements-andStages.pdf

7. Global Forum on Innovation in Health Professional Education; Board on Global Health; Institute of Medicine. The bridging leadership framework. In: Building health workforce capacity through community-based health professional education. Workshop summary. Washington, DC: National Academies Press; 2015. Pp. 189-190.

8. World Health Organization. WHO global competency model [Internet]. n.d. [cited 2019 Apr 24]. Available from: https://www. who.int/employment/competencies/WHO_competencies_EN.pdf

9. Lewin K. Frontiers in group dynamics: Concept, method and reality in social science; social equilibria and social change. Hum Relations. 1947; 1(1):5-41. doi: 10.1177/001872674700100103.

10. Kübler Ross E, Wessler S, Avioli L V. On Death and Dying. JAMA. 1972; 221(2):174-9. doi: 10.1001/jama.1972.03200150040010

11. Kotter JP. Leading change: Why transformation efforts fail. Harvard Business Review. 1995:60-7.

12. Rogers EM. Diffusion of innovations, 3rd ed. New York, NY: The Free Press; 1983.

\section{The Acta Medica Philippina is now accepting limited advertising for its front and back cover (colored), as well as for available spaces in some of its pages, as appropriate. For inquiries and submission of proposals, please email us at actamedicaphilippina.upm@up.edu.ph}

